\title{
Declining Enrolment Sparks Certificate Review: Lessons Learned
}

\author{
Susan Hutton, University of Calgary
}

\begin{abstract}
The design of the Human Resource Management Certificate at the University of Calgary was the culmination of a two-year review process. Although the issue of declining enrolment initiated the review, many other issues became apparent. The process of informal and formal investigations that were undertaken are outlined, as are the actions taken. The challenges of resource constraints, collaborative investigation, the climate of competition in post-secondary institutions, and issues of credit transferability are highlighted along with the lessons learned. The process and results may benefit other continuing education programmers.
\end{abstract}

\begin{abstract}
RÉSUMÉ
Pendant deux ans, on a entrepris un processus de révision et son apogée fut la conception du Certificat en Gestion des ressources humaines à l'University of Calgary. Bien que le sujet d'une inscription en déclin ait initié cette révision, beaucoup d'autres questions se sont présentées. Le processus d'enquête officielle et d'enquête non formalisée suivie est décrit, ainsi que les actions entreprises. Les défis de limites financières, d'enquête en collaboration, de climat de compétition dans les établissements d'enseignement postsecondaire et de questions d'admissibilité de crédits sont soulignés ainsi que les leçons apprises. Ce processus de révision et son résultat pourraient aider d'autres programmeurs en éducation permanente.
\end{abstract}




\section{INTRODUCTION}

The Faculty of Continuing Education at the University of Calgary has offered Management Certificate programs for over 20 years. In the summer of 1993, a review of the Human Resource Development and the Personnel Administration Certificate programs was initiated; these programs had not had a thorough review since their inception. While enrolment in the Human Resource Development Certificate Program had fallen from 305 students in 1991 to 173 by 1995, enrolment in the Personnel Administration Certificate had dropped to 275 students (from 655) over the same time period. After an initial, informal investigation, two advisory committees were formed to explore the possible causes of the declining enrolment and to make recommendations for subsequent action. Possible causes were explored, questions posed, and data gathered over a two-year period, and the investigations culminated in a structure being set to implement change. The review provided numerous insights, some expected but many not.

Although the review did answer many of our original questions, it also taught us a great deal about the realities of conducting a comprehensive program review. In particular, the two-year review process revealed much about what busy practitioners need to investigate in order to revitalize long-standing programs. Time and financial constraints were constant realities throughout this review. In January of 1994 the Alberta Minister of Advanced Education, Jack Ady, announced sweeping changes to the way the Alberta government would provide money to higher education institutions. Budget reduction targets of 14.2 percent by 1996-97 were announced at the same time as institutions were told there would be an increased focus on accountability and a rewarding of institutional performance (Alberta Government News Release, Jan. 18, 1994). Thus, the Faculty of Continuing Education was faced with dramatic changes in provincial funding, and continuing education programs in Alberta are now operating under increasingly limited resources and within increasing time constraints to generate greater revenues. Doing more with less appears to be a trend for those charged with directing continuing education programs.

What follows is an account of the two-year review process and the actions taken to redesign two certificates within the Management Certificate programs. The author of this paper was largely responsible for guiding the review and for the subsequent redesign of the certificates. This account is based on advisory committee meetings, conversations with other administrative programmers, staff in the Faculty, professional association 
representatives, and a written survey administered to both students and employers involved with the Human Resource Development and Personnel Administration Certificates. A number of salient issues emerged that may be of interest to other program administrators who are facing declining enrolments, lack of administrative time, and few resources to investigate and implement needed changes.

\section{The Human Resource Development}

\section{And Personnel Certificates}

The Human Resource and Personnel Administration Certificate Programs consist of 300 hours each, offered in a format of 30- and 40- hour evening courses. Approximately 60 evening courses are offered one night a week, from two and one-half to three hours each, for 11-13 weeks during the Fall and Winter terms. A six-week Spring term offers 6-8 courses in a more condensed format of 6 hours a day on Saturdays or 3 hours a night, two nights a week. Core and optional courses are quite similar for both the certificates (see Figure 1). Upon completion of 300 hours of instruction, students receive a Business Management Certificate from the University of Calgary. In addition, the certificates have the endorsement and support of professional organizations, and many students gain credit towards their professional designation by completing courses in the certificate programs.

The Personnel Administration Certificate (instituted over 25 years ago) and the Human Resource Development Certificate (first offered 15 years ago) have both enjoyed a long history of serving the training needs of fulltime employed adults in the Calgary area. They have traditionally been well supported by large public and private organizations such as Nova, TransAlta, Shell, City of Calgary, Esso, and Husky. For example, many employers have typically paid 100 percent of students' fees upon their successful completion of courses, and several have donated downtown corporate space for classes at a slightly reduced tuition rate for their employees attending certificate courses. However, despite this history of large organizational support, these certificate programs began experiencing declining enrolment in the early 1990s. 


\section{FIGURE 1}

\section{Management Certificate Programs}

Faculty of Continuing Education, University of Calgary, 1980-1995

\begin{tabular}{l} 
Personnel Administration \\
Compulsory Courses \\
\hline Business Management or \\
Public Administration \\
Human Behaviour in Organizations \\
Management Communications \\
Personnel Management \\
Development Microeconomics or \\
Macroeconomics \\
Microcomputers Today plus \\
One computer short course \\
Optional Courses
\end{tabular}

Overview of Human Resource

Development

Administration of Employee Benefits

Labour Relations

Techniques of Interviewing

Wage and Salary Administration

\section{Human Resource Development}

Compulsory Courses

Business Management or

Public Administration

Human Behaviour in Organizations

Management Communications

Personnel Management

Overview of Human Resource

\section{Optional Courses}

Program Development and

Evaluation

Instructional Techniques and

Resources

Organizational Development

Career Management

\section{Individual Component}

45 hours of approved seminars or An approved practicum project or An approved 30-hour certificate course 


\section{Issue of Declining EnRolment: The Questions}

With a clear mandate to revitalize the certificate programs and improve enrolment, we began the review with the following questions.

- Is this happening to other Human Resource Development and Personnel Administration Certificate programs in our geographical area?

- Where are the students going, that is, is there increased competition from other institutions?

- Are there fewer training dollars available from the large corporations for whom these programs have been a mainstay for staff training over the last 20 years?

- Is it the lack of relevancy and / or the currency of course content?

- How do we know the level of quality of our instructors-what is the evaluation method?

- Are we splitting our market by having two certificates in a similar area?

- Are we failing to market our courses effectively?

-What resources do we have to conduct a comprehensive review?

These initial questions directed the informal inquiry that subsequently led to the formation of two advisory committees and included a comprehensive survey of students and employers.

\section{GATHERING INFORMATION}

\section{Informal Inquiry}

The investigation began with extensive conversations with the program assistant who had been with the certificate programs from their inception. Enrolment data, available since 1984, indicated that the Human Resource Development and Personnel Administration Certificate programs had experienced a steady decline since 1990 (see Table 1 for detailed enrolment patterns). As the initial development of the Personnel Administration Certificate was done in conjunction with the University of Alberta, the current director was contacted; the enrolment in its Personnel 
Articles

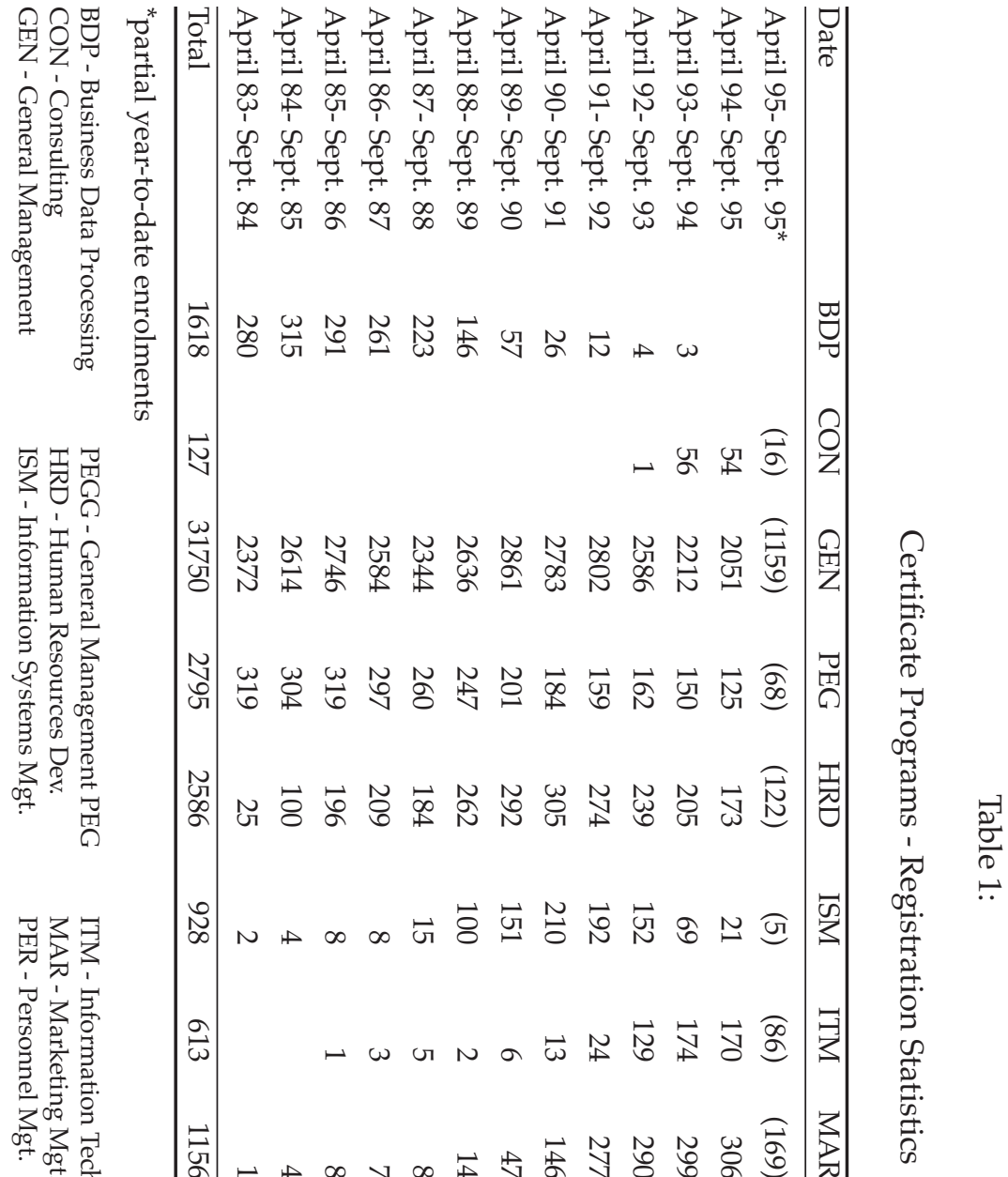


Administration Certificate had declined at a more rapid pace than ours, the decline attributed in part to the opening of Grant MacEwan College's Human Resource program. This director believed that Grant MacEwan's program was perceived by students as having more current content, a more flexible format, and instructors who had more recent and relevant work experience than those in the University of Alberta's Personnel Administration Certificate program. Discussions with the director of Grant MacEwan's new Human Resource program confirmed these observations and indicated that competition was a likely factor in the declining enrolment of the University of Alberta's program.

A factor that appeared instrumental to the Calgary post-secondary situation was the recent availability of degree credit at both Mount Royal College (MRC) and the Southern Alberta Institute of Technology (SAIT). Contact with MRC indicated that many students who had formerly enroled in MRC's Management Certificate programs were now showing increased interest in the now-offered Business and Entrepreneurial applied degree program. Similarly, the recent degree status at SAIT was influencing the course selection of many students at this institute. Although previous efforts were made to secure degree credit (Garrison \& Kirby, 1995), the Faculty of Continuing Education's certificate programs were currently not transferable to degree credit, in contrast to the degree credit now available at MRC and SAIT.

While attending the local Human Resource Association's monthly meeting, conversations with two human resource directors from oil and gas industries confirmed that training dollars to assist students in courses were indeed shrinking. Financial considerations led one of our business partners to sublease portions of its building, which left the University of Calgary's program with one less downtown location for course offerings. The economy and competition did seem to be contributing factors to the decline in enrolment.

Further discussions with executives of the Human Resource Association revealed that the competencies for human resource professionals were being revised. The Human Resource and Personnel roles were being integrated, as the two roles were no longer seen as entirely separate and the competencies required of current practitioners in this field were therefore changing (see Figure 2). A cursory review indicated that our program content no longer appeared to have a clear alignment with the Human Resource Association's list of competencies and needed updating to remain 


\section{Figure 2}

\section{HR Competencies and Professional Development Human Resource Institute of Alberta, February 1995}

\section{HR Technical Proficiency:}

HR Planning, Selection,

Placement

Training and Development

Employee and Labour

Relations

Compensation and Benefits

Health, Safety and Security

Personnel Research

Organization Design

HRIS

\section{Business Knowledge:}

Strategic Focus

Organizational Awareness

Industry Knowledge

Value-Added Perspective

General Management Skills
Influence Management:

Perceptual Objectivity

Coalition/Network Building

Communication Process

Skills

Negotiation Skills

Functional and Organizational Leadership:

Developing Others

Group Management Skills

Functional Marketing

Leading Through Vision

Integrity

Goal and Action Management:

Efficiency Orientation

Proactivity

Concern with Impact

Decisiveness 
relevant, yet another possible contributing factor to our declining enrolment.

Conversations with the program assistant, instructors, students, and staff in our program determined that the instructor evaluation process had not been updated for several years, and many felt there were significant gaps in the information on the quality of instruction currently being received. For example, they noted that the substance of evaluative questions was not always relevant, and that the return of information was not timely. It was also noted that the Faculty appeared to be following fairly traditional marketing procedures, relying almost exclusively on the Faculty calendar and local newspaper ads. Perhaps instructional quality and marketing were also factors contributing to our declining enrolment.

From these informal investigations, we recognized the need for a more formal review process than was first envisioned. This would not be a short, quick-fix assessment. We needed the advice of staff, students, other continuing education programmers, and professionals in the field, and we had shrinking resources and limited time in which to obtain it. We needed a task-specific committee with a clear mandate and the authority to both formally investigate the reasons for declining enrolment and recommend needed changes. Utilizing existing resources was essential. Colleagues in the Faculty of Continuing Education brought together 15 peoplerepresenting instructors, students, and faculty from our programs, directors from other institutions, business professionals from companies sending students to our program, and executive members from professional organizations - to form our first advisory committee. The committee met on a biweekly basis for approximately one year.

\section{The First Advisory Committee}

This committee needed to understand the history and the current nature of the certificate programs before utilizing its own expertise to explore reasons for the declining enrolment, and begin to address future alterations. This need to discover where we were and where we needed to be before recommending what needed to be done to close the gap between the current state of affairs and the preferred future state of affairs is a common and well-accepted method of program planning in adult and continuing education (Hanson, 1991). After weeks of presentations from programmers and professional association representatives, of speculation about the reasons for declining enrolments, and of dialogue amongst committee members, the committee felt it had gained a thorough understanding of the 
nature of the two certificate programs. Although the members felt they had many ideas about changes that might be made to increase enrolment, they wanted current quantitative data from students and employers to validate their growing understanding and thus recommended that a student/ employer survey be conducted.

Resource limitations, in the form of the director's time, the time of those serving on the committee, and financial constraints, led to a brief hiatus during the late spring of 1995 during which options for survey development and analysis were explored. Developing a survey would be both time-consuming and expensive. Deciding not to "re-invent the wheel," other continuing education directors in Western Canada were contacted, whereupon it was discovered that the University of Manitoba had recently conducted a survey of its certificate programs and was willing to share the results. The University of Calgary's Office of Institute Analysis assisted in the redesign and tabulation of survey data at no additional cost to our program. The early summer was spent designing and piloting the survey with members of the Advisory Committee. By the end of the summer, the survey was given University ethics approval, and then successfully piloted, printed, and mailed to students and employers.

\section{The Student/Employer Survey}

The survey was mailed to all 505 students enroled in the Human Resource Development and Personnel Administration Certificate programs.

Advisory Committee members recommended that the survey be mailed to 63 employers who had either middle-management people or others responsible for human resource or personnel functions in their organizations. The student response rate was 35 percent (175 students completed the survey); the employer response rate was 48 percent (30 employers completed the survey). Most employers and students who responded were from large organizations (over 1000 employees).

Students who responded were nearly equally divided between the Personnel Administration Certificate (50 percent) and the Human Resource Development Certificate (45 percent), with the remainder enroled in both certificate programs. Approximately one-third of these students (31 percent) held university degrees; most had not taken other certificate programs (65 percent); and some (21 percent) had professional designations. Most students were full-time employees (86 percent), equally distributed in clerical/administrative, supervisory / first-level management, technical, or middle-management positions. A few (7 percent) were from senior 
management. About half the students were either preparing to supervise others directly (46 percent) or were presently supervising between 1-10 other employees (41 percent). Most had been in the workforce for 1 to 10 years (80 percent), and were between 26 and 40 years of age (66 percent).

Employers, although familiar with the two certificate programs (87 percent indicated a high level of awareness of the program), reported that more advertising would help make the programs even better known to the community and that transferability of credit to degree programs would provide more credibility to the certificates. Most felt more articulation of content was needed, as was collapsing the two certificates into one. General support was indicated as most employers noted that they would continue, within budget constraints, to support employees with a fee reimbursement upon their successful completion of the course work.

Students indicated they were generally satisfied with the course and program offerings. Specifically, they felt that the program challenged them intellectually (83 percent), was good value for the time spent (87 percent), and was relevant to their work (73 percent); that tuition fees were reasonable (74 percent); and that the mix of required and optional courses was about right (76 percent). Although 62 percent of those responding saw seminars as fairly beneficial, many were undecided about this aspect of the certificate and required clarification of the seminar options. Similarly, the optional practicum/ project was not well understood, with 47 percent of students undecided as to its value and noting that further clarification of this option was also needed.

Students' reasons for enroling in the programs included: to broaden my knowledge (87 percent), to improve my existing job skills (74 percent), the challenge and stimulation of continued learning (68 percent), to prepare for advancement (67 percent), interest in subject matter of courses (61 percent), to prepare for a new job or career (56 percent), to meet people with similar career interests (31 percent), to increase present salary (30 percent), to prepare for professional accreditation (21 percent), and other miscellaneous reasons. Employers' reasons for paying student fees in the programs mirrored those of the students.

The survey provided valuable information, but its relevancy to the issue of declining enrolment was still uncertain. Although the survey data had been tabulated by the Office of Institute Analysis, it needed critical analysis before the Advisory Committee could make quality recommendations. Progress on this aspect began when a contract consultant was hired to provide an executive summary of the survey data and to help formulate the 
membership of the second Advisory Committee (since original members agreed to serve for only one year); the consultant would also summarize all the findings of this second committee.

\section{Executive Summary of the Student and Employer Survey}

The second Advisory Committee began its work by reviewing the survey data. Eight major themes and subsequent rationales had been compiled from the survey data by the consultant.

1. The programs were seen to be meeting specific needs and were valued by both students and employers. This was evidenced by the high level of awareness of the programs, the financial support given to students via fee payment by employers, and the relative consistency of the employer and student perceptions of the value of the programs - both to their knowledge and job skill development and to their personal growth and development or lifelong learning opportunities.

2. The majority of employers and students accessing these programs were from large for-profit organizations or from government. For example, 43 percent of employers and 32 percent of students responding were from financial/insurance and oil and gas industries, whereas 18 percent of employers and 23 percent of students were from government organizations. In each case, those responding were primarily (66 percent) from organizations with over 1000 employees; thus, there was little evidence that small company training needs were being served.

3. The motivation of most students for taking the programs was oriented to personal/job satisfaction, not to a salary increase; some indicated that potential "career" change due to the threat of down-sizing was also a motivating factor. Specifically, the top two reasons cited by employers and students were to "broaden knowledge" and to "improve existing job skills." Students also made some reference (as noted above) to preparing for a new job or career.

4. The practicums and seminars were ambiguously perceived by both employers and students. Feedback indicated a lack of clarity about the structure of these options, the prohibitive cost for seminars, and the general lack of knowledge that these options existed. Yet, at the same time, a general interest (particularly from students) was expressed in the value of both.

5. There was an overall perception that the marketing of the programs could be enhanced. Students provided many suggestions, with specific 
reference to soliciting satisfied graduates and employers who could provide testimonials about the value of these programs. Employers suggested that clarity of content between programs was needed.

6. The lack of transferability of degree credit for the courses and for the management certificate programs as a whole was identified as an area of concern by both students and employers. Employers expressed that transferability to a degree program would lend more credibility to the programs, and students indicated that, even though they had a certificate, they felt those with degrees had more credibility and were favoured for advancement.

7. Both instructor qualities and classroom climate were seen as significant factors in the programs' success. Students valued instructor qualities such as knowledge of subject matter, preparedness and organization, communication, and interpersonal skills, and they wanted a classroom climate that was flexible, interactive, relaxing yet challenging. They indicated that although this was generally the case, there were exceptions.

8. There were mixed perceptions from students on the value of integrating the two program areas. Some students expressed an appreciation for introducing "levels" as an option or broadening the content of courses. Employers, as noted previously, favoured one certificate. Many respondents indicated that course content was generally good, but needed an update to include areas such as computer graphics, enhanced group work, public speaking skills, and managing down-sizing.

It appeared that by most indications the programs were "working" relatively well. Specific enhancements, however, could enrich their capacity to remain current in a locally dynamic organizational climate.

\section{The Second Advisory Committee}

The second Advisory Committee of 12 people (3 people continued from the previous committee) was struck to utilize the information the first committee had gathered and to provide recommendations. Representation on the second committee was similar to that of the first. Its task was to doublecheck the data before making crucial decisions about the changes needed in the certificates. Members were given an overview of the first Advisory Committee's efforts and a complete set of survey findings, and then were asked to review the material in advance of attending three taskspecific, time-limited meetings of two hours each. 
The focus of the first meeting was to answer any questions regarding the efforts of the first committee and its survey findings. The second meeting dealt with the question: "If you could have only 8-10 courses in one certificate, what would they be?" The final meeting was to detail the content of the suggested courses determined at the second meeting. The second Advisory Committee provided a set of recommendations that addressed many of the initial questions about the direction in which the two certificates in question should be taken to improve enrolment.

\section{IMPLeMENTing ChANGe: The ANSWERS}

After two years of review, utilizing a combination of informal and formal techniques, many of our original questions were, in fact, answered. The Faculty of Continuing Education was not alone in its state of declining enrolment. Competition from other institutions that had recently designed programs with more current content and more flexible options and that were also providing opportunities for degree credit transfer was certainly a factor. Although we continued to have support from large companies, there were fewer training dollars; therefore, we needed to clarify the components of our programs and improve marketing to our present clients, as well as to those we were not currently reaching, such as smaller, more down-sized organizations. Course content and certificate format, while adequate, did need updating to meet new student, employer, and professional accreditation standards. New topics and an integrated certificate would help us to provide relevant training in a more effective and efficient manner. The quality of instruction appeared satisfactory; however, a review of the instructional evaluation process was needed. As a result of the information obtained, many changes were made in the design and content of the certificates.

\section{Certificate in Human Resource Management}

The primary concern was to immediately collapse the two certificates into one in order to reflect the changing profile of student and industry needs and to eliminate the competitive aspect of offering two very similar programs (see Figure 3). It was also determined that core courses would continue to be offered in the two key areas of Human Resource and Personnel Administration as a foundation for future study in more specialized areas. Flexibility would be provided by allowing students to take optional courses from those offered in the General Business 


\section{Figure 3}

\section{Management Certificate Programs}

Faculty of Continuing Education, University of Calgary, 1996

\section{Human Resource Management Certificate}

\section{Compulsory Courses}

Business Management: Business Planning and Operations

Human Behaviour in Organizations: Effective Management

Management Communication: Interpersonal Communication Skills

Human Resource Management: Recruitment, Evaluation and

Compensation

Training, and Performance Improvement

$\underline{\text { Required Project }}$

Human Resource Management Project

\section{Optional Courses}

Customize your program to meet individual learning goals, organizational needs, or preparation for the Human Resource Management Project. To complete the 60 hours of the optional component, we recommend courses from the following list OR you may select any of the optional courses offered through the General Management Program.

- Administration of Employee Benefits

- Business Ethics

- Career Management

- Collaboration: Making Partnerships Work

- Communication for Bridging the Gender Gap

- Cultural Diversity: Creating Inclusionary Business Environments

- Learning in the Workplace

- Instructional Techniques and Resources 
Management Certificate program. A student project (which provided students with the opportunity to explore a content area in more depth) would now be required rather than being optional. An increased marketing effort clarified the seminar option. Finally, in some cases, courses were given minor face-lifts, for example, the infusion of new topics within the courses, the addition of more accurate or up-to-date course titles, and the incorporation of new activities or resources. In other cases, entire topics were deleted.

\section{DisCUSSION}

\section{Related Issues}

Although a redesign of the certificate was the major result of the review, many related issues surfaced and various lessons were learned about how to conduct such reviews in the future. First, the input of professional associations is key to remaining current and viable. For example, the local Human Resource Association was involved in the entire review process, it reviewed and approved changes, and it was asked to confirm its support of the new certificate. One professional association representative spoke highly of the new changes at the spring graduation ceremony.

Second, feedback from all stakeholders is critical to successful certificate revisions. After this review, a new committee of students, staff, and instructors was immediately struck to begin working on revising the entire certificate evaluation process, procedures, and forms. In addition, communication with instructors was improved by providing them with a summary of the findings from the student and employer surveys and the instructor issues / concerns expressed.

Third, the information gained in this review was shared with the University registrar and undergraduate committees with the goal of obtaining transferability of certificate credit to undergraduate degree credit, thus beginning the process necessary to accomplish this goal.

\section{Lessons: Reflecting on Our Learning}

Although we learned a great deal about the specific issue of declining enrolment, perhaps the most valuable lessons were more systemic and have broader implications for the Faculty as a whole. With limited resources, it is paramount for programmers and continuing education practitioners to examine closely the resources within their institutions (Caffarella, 1994); 
Pfeffer, 1994). In this case, the advice and assistance received from former continuing education directors served to speed the inquiry process. As well, the time and expertise given by instructors, employer organizations, professional associations, and human resource professionals were crucial to the review process. The University's Office of Institute Analysis provided much needed statistical data from the survey at no cost to the Faculty. Without such shared information and other resources, much time and effort would have been wasted while enrolments continued to decline.

For the busy continuing education programmer, immediate administrative tasks seem to consume each day. However, carving out time to do quality, consistent review places programs in a preventative state rather than a reactive one. The review outlined here not only prevented the program from failing, but also assisted in an examination of professional development needs in light of the program review. Conducting a personal audit of our own adult education practices is something Mills (1991) notes as critical to developing our future plans of action. Scheduling a percentage of time to prepare for the future is essential to the survival and growth of current programs. Reactive discontinuation of programs that may well deserve to survive may be the result if time is not allotted for critically reflective review (Sork, 1991). A comprehensive review process must be based on sound review processes (Berk \& Rossi, 1990; Schaffer, 1988), and adequate but effective time must be scheduled for such reviews. Controlling the task and the time commitment for those involved in it is essential to gain commitment and to move purposefully ahead.

\section{Closing Comment}

Working collaboratively and learning from others were the key lessons of this review. Conceptualizing the issue of declining enrolment was something we needed to do, but, we did not need to do it in isolation or without the assistance that could be gained from others, at times without great financial costs. Asking for assistance and inviting the efforts and contributions of others resulted in both new and renewed partnerships with other institutions, employers, and professional associations. We gained valued partners both locally and regionally for future initiatives. By asking for assistance, we avoided the mistakes and learned valuable lessons from the "failures" of others (Caffarella, 1994; Lewis \& Dunlop, 1991).

Another critical lesson we learned was to be prepared to address related issues that surfaced. Great ideas emerged from the original question of 
declining enrolment. For example, the entire instructor evaluation procedure has been revised from an outdated, data-based process to a new, computer-scanned form. Now instructors and programmers have access to relevant and timely information to improve instructional techniques and course offerings on a term-by-term basis. Still another related issue that emerged resulted in the approval of the transferability of certificate credit to degree credit, which is particularly rewarding not only for our students but also for prospective certificate students from across Canada. Working collaboratively, we learned that personal effort and collective political will did make a difference in changing a long-standing assumption that nondegree certificate credit is not transferable to undergraduate degree credit. Through the review committees' efforts, supported by the survey findings, the petitions from students and employers, and the cooperation of professional associations, faculties, and committees within the University, the certificates are now transferable to an undergraduate degree. This was in part a result of our own efforts, of the collective efforts of those noted above, and of the impact of competition from other institutions.

Although declining enrolment was the presenting issue of this review, we ended up addressing a potpourri of issues and changing many aspects of the program and the program planning process. The initial question of declining enrolment necessarily evolved into a much-needed, two-year review in which we learned and changed much more than we ever anticipated.

\section{ACKNOWLEDGMENT}

The author would like to acknowledge the contributions of contract consultant Emily K. Mansfield.

\section{REFERENCES}

Alberta Advanced Education and Career Development. Major changes to funding of public post-secondary institutions (News Release, Jan. 18, 1994).

Berk B., \& Rossi, P. (1990). Thinking about program evaluation. Newbury Park: Sage Publications.

Caffarella, R. (1994). Planning programs for adult learners: A practical guide for educators, trainers and staff developers. San Francisco: Jossey-Bass. 
Garrison, R., \& Kirby, D. (1995). Developing a master of continuing education degree program: The way it was! Canadian Journal of University Continuing Education 21 (2), 7-20.

Hanson, A.L. (1991). Understanding participation in programs. New Directions of Adult and Continuing Education 49 (Spring), 29-41.

Lewis, C., \& Dunlop, C. (1991). Successful and unsuccessful adult education programs: Perceptions, explanations, and implications. New Directions for Adult and Continuing Education 49 (Spring), 15-28.

Mills, H. (1991). Responding to success and failure. New Directions for Adult and Continuing Education 49 (Spring), 81-88.

Pfeffer, J. (1994). Competitive advantage through people. Boston: Harvard Business School Press.

Schaffer, R. (1988). The breakthrough strategy: Using short-term successes to build the high performance organization. New York: Harper Business.

Sork, T. (1991). Tools for planning better programs. New Directions for Adult and Continuing Education 49 (Spring), 89-96.

\section{BIOGRAPHY}

Susan Hutton is Associate Dean and Director of the Masters in Continuing Education: Workplace Learning in the Faculty of Continuing Education at the University of Calgary and formerly the Director of Management Certificate Programs.

Susan Hutton est Doyenne associée ainsi que Directrice des Maîtres en Éducation permanente: Le Milieu du travail à la Faculté d'Éducation permanente à l'University of Calgary et elle est anciennement la Directrice des Programmes de certificat en gestion. 